\title{
Mitogen stimulation activates different signaling pathways in early- and late-divided $T$ cells as revealed by cDNA microarray analysis
}

\author{
YUFENG LI ${ }^{1,2}$, KWONG-KWOK WONG ${ }^{2}$, SATOKO MATSUEDA $^{2}$, CLAY L. EFFERSON ${ }^{2}$, \\ DAVID Z. CHANG ${ }^{3}$, CONSTANTIN G. IOANNIDES $^{2}$ and NAOTAKE TSUDA ${ }^{2}$
}

\author{
${ }^{1}$ Graduate School of Biomedical Science, UT Health Science Center at Houston; ${ }^{2}$ Departments of Gynecologic Oncology \\ and ${ }^{3}$ GI-Medical Oncology, MD Anderson Cancer Center, Houston, TX 77030, USA
}

Received June 20, 2006; Accepted August 17, 2006

\begin{abstract}
Mobilization of tumor-reactive $\mathrm{CD}^{+} \mathrm{T}$ cells remains the major challenge of cancer immunotherapy. Knowing how and when the $\mathrm{T}$ cell response expands and differentiates after antigen stimulation would make a significant contribution to the development of tumor vaccines. In the current study, we used CFSE-based cell sorting and cDNA microarray to identify the gene expression profile of adjacent generations of $\mathrm{T}$ cells after PHA stimulation. Early-divided generations of $\mathrm{T}$ cells responded to stimulation by activating cell cycle and surviving gene pathways, while late generations of T cells had more dramatic changes in transcription of cytokine genes. Reconstruction of biochemical pathways, activated in both early and late generations of $\mathrm{T}$ cells, also confirmed the impact of division in focal-adhesion kinases. Because most tumors are infiltrated by lymphocytes, our studies indicate a novel approach to identify 'systemic biological responses' of T cells, which could determine the design, and optimization of effective tumor vaccines.
\end{abstract}

\section{Introduction}

Studies in previous years have focused on the identification and characterization of tumor antigens recognized by $\mathrm{T}$ cells.

Correspondence to: Dr Constantin G. Ioannides, Department of Gynecologic Oncology, MD Anderson Cancer Center, 1515 Holcombe Blvd., Box 304, Houston, TX 77030, USA

E-mail: cioannid@mdanderson.org.

Abbreviations: HER-2, HER-2 protooncogene; IFN- $\gamma$, interferon $\gamma$; CFSE, carboxy-fluorescein acetate; PHA, phytohaemagglutinin; TIL, tumor infiltrating lymphocytes; MFI, mean fluorescence intensity; FA, focal adhesion; MAPK, mitogen activated protein kinase; PKC, protein kinase C; ERK, extracellular signal regulated kinase

Key words: gene transcription profile, $\mathrm{T}$ lymphocytes, cancer vaccine, focal adhesion kinase, cytokine-cytokine receptor
Among these tumor antigens, some consist of tumor proteins, which are present at low levels in healthy tissue, such as HER-2 and Folate receptor $\alpha(1,2)$. The processes of malignant transformation and metastasis coincide with increased amounts of these proteins. The increased amount of these proteins apparently coincides with the presence of $\mathrm{CD} 8^{+}$cells, which recognize peptides from these proteins. The $\mathrm{CD} 8^{+}$cells, present in malignant effusions, become activated by culture in the presence of IL-2, and mediate lysis of autologous tumors (3-5). Such cells are also present in healthy individuals $(4,5)$. These results raise the novel hypothesis that immunity to cancer is induced in vivo by self-vaccination. Administration of a peptide HER-2 vaccine to cancer patients at high risk of metastasis resulted in at least 9- to 11-month delays in occurrence of metastasis in the vaccinated group compared with the nonvaccinated patients (6). In contrast, in patients with progressive disease dominated by an increased level of the prostate specific antigen, the same vaccine was insufficient to delay disease recurrence (7).

These findings together raise the need for characterization of the immune response potential of the T cells in an individual, before and after cancer vaccination. The potential of $\mathrm{T}$ cells to respond to antigen will indicate whether a cancer vaccine is expected to function as intended or not. Therefore it is important to elucidate which responses should be considered as indicators of activation.

The response of a $\mathrm{T}$ cell to a stimulus is characterized by cell division followed by differentiation $(8,9)$. Cell division results in several successive generations of daughter cells, while differentiation is characterized by activation of transcription of cytokine genes (8). Cell division precedes expression of cytokine genes. Transcription products of cytokine genes are in general detectable after 2-3 divisions (10). The presence of cytokines in the activation environment polarizes the $\mathrm{T}$ cell response towards a type 1,2 , T regulatory phenotype or T-inflammatory phenotype (11-13). A large amount of work has been recently performed in characterization of the transcriptional profile of $\mathrm{T}$ cells from various sources after stimulation with antigen and cytokines (14-16).

To identify the activation potential and the early-activated genes in $\mathrm{T}$ cells, in this study, we re-examined this question using microarray technologies. We also hypothesized that the 
gene-pathways of activated $\mathrm{T}$ cells interact, and the responses are 'global' rather than associated with restricted specific pathways of differentiation. Expression of the transcripts of the genes encoding effector cytokine molecules (IFN- $\gamma$, perforin, granzyme) in lymphocytes associated with tumor cells only indicate that a response to the tumor exists. It does not however indicate that this response can expand to proliferation of $\mathrm{T}$ cells at re-activation with antigen/tumor Ag. Less differentiated $\mathrm{T}$ cells will expand and complete their differentiation program while more differentiated cells will die by $\mathrm{T}$ cell receptorinduced apoptosis.

If this hypothesis is correct then the transcriptional profile of $\mathrm{T}$ cells should change with the cell division. In this case genes other than the ones encoding for cytokines and effectorproteases will be activated first. Furthermore T cells expressing such functional signatures will die at re-stimulation. The response to vaccine will recapitulate division and differentiation of new generations of naïve T cells.

\section{Materials and methods}

Reagents and technical support. RNA extraction kits were obtained from Qiagen (Valencia, CA). Carboxy-fluorescein acetate (CFSE) was obtained from Invitrogen (Carlsbad, CA) and stored in aliquots at $4^{\circ} \mathrm{C}$. Phytohaemagglutinin (PHA) obtained from Gibco (Carlsbad, CA), was reconstituted at $1 \mathrm{mg} / \mathrm{ml}$ and stored frozen in aliquots. The RNA samples were separately analyzed by the Genomics Core Resource in MD Anderson Cancer Center and Agilent Technologies, Inc. (Palo Alto, CA). The Onto analysis software programs for microarrays were available online at http://vortex.cs.wayne. edu/ontoexpress/ (17).

CFSE labeling and PHA stimulation. Peripheral blood mononuclear cells (PBMC) were isolated by Ficoll-centrifugation and resuspended in PBS. PBMC were suspended in CFSE solution of $5 \mu \mathrm{M}$. After 10-min incubation, unincorporated CFSE was washed out by dilution in PBS, followed by centrifugation (18). CFSE-labeled lymphocytes were suspended into RPMI culture media containing $10 \%$ FCS. PHA $(5 \mu \mathrm{g} / \mathrm{ml})$ was added per $1 \times 10^{5}$ CFSE-labeled lymphocytes. Lymphocytes were analyzed by flow cytometry for 4 consecutive days to verify their division (Fig. 1). Sterile flow-cytometry sorting was performed for separation of different generations of $\mathrm{T}$ cells, at Baylor College of Medicine, based on the dilution of CFSE (Fig. 2).

RNA isolation and gene chip hybridization. We used TRIzol reagent for isolation of total RNA from cultured cells ( $1 \mathrm{ml}$ of TRIzol per 5-10x $10^{6}$ cells), followed by chloroform/isopropyl alcohol precipitation of RNA. All the above procedures were performed in an RNase-free environment. Total RNA isolated using TRIzol was further purified using the Qiagen RNeasy cleanup procedure. The A260/A280 ratio was at least 1.9 for purified RNA. The quality of RNA was also assessed by agarose gel electrophoresis, in which the 28S band was 2-fold more intense than the $18 \mathrm{~S}$ ribosomal RNA band. The RNA preparation was free from genomic DNA contamination.

RNAs from activated generation 1 and undivided $\mathrm{T}$ cells were analyzed using chips available from the Genomics Core
Resource in MD Anderson Cancer Center (19). RNAs from activated generation 4 and generation $3 \mathrm{~T}$ cells were handled as follows: starting from total RNA, the cDNA synthesis was conducted with $\mathrm{Cy} 3$ and $\mathrm{Cy} 5$ fluorescence modified nucleotides being introduced inside, according to the manufacturer's (Agilent Technologies, Inc.) specifications with corresponding dye swaps. Both overnight hybridization and wash protocols were strictly followed for acquiring useful data.

Analysis of microarray results. The variability of the measurements was estimated using replicate spotting for each gene transcript on the array. When comparing the two channels, The smooth curves that estimate the within-channel standard deviation of the values of the two channels, were pooled to produce a single curve estimating the standard deviation $(\Sigma)$ across the entire array, The smoothed t-statistic was computed as t-score $=[\log (\mathrm{b})-\log (\mathrm{a})]$ divided by standard deviation $(\Sigma)$, for each gene transcript. We selected the differentially expressed genes using a cut-off of t-score of 3.0. The smoothed $t$-score value is an estimate of the log ratio of gene expression levels between samples that have been re-scaled to account for the observed variability between the two determinations for each transcript.

To refine the gene expression profiles of divided $\mathrm{T}$ lymphocytes we used the Agilent Human 1 cDNA microarrays (G4100A) (20). These chips contain 12,814 unique clones. After hybridization, the Agilent gene chips were scanned by an Agilent DNA microarray scanner into the TIF (Tag Image File) format, analyzed with Feature Extraction Software version 5.1.1 (Agilent Technologies, Inc.), which uses the LOWESS (locally weighed linear regression curve fit) normalization method. The background signals were subtracted and the expression values of individual genes were obtained as the $\log$ ratio of the dye-normalized red ( $\mathrm{Cy} 5)$ and dye-normalized green (Cy 3) channel signals. By comparing plots showing the results of designed array versus its dye-swap hybridization array, statistically significant $(\mathrm{p}<0.01)$ data points in both hybridizations were identified based on their individual fold increase between the two generations. Transcripts that indicated unchanged gene expression $(\mathrm{p}>0.01)$ and discordant results in two dye-swapped chips (having a positive slope in plot comparison) were not taken into consideration.

To better characterize the functionally-related genes which showed different expression levels between the two pairs of generations of $\mathrm{T}$ cells ( 1 versus 0 , and 4 versus 3 ), we used the Onto-Express program $(21,22)$ to research the following functional categories: biological processes, cellular roles, and molecular functions. Data were inputted with the Binomial distribution and Bonferonni correction. To construct gene pathways as graphical representations of gene interactions, the software performed searches based on the inputted information in the KEGG (Kyoto Encyclopedia of Genes and Genomes) database. The Onto-Pathway Express program (17) was also utilized to identify the biologically meaningful increase/decrease in gene transcription. The data were analyzed with hyper-geometric distribution, the probability model best suited to calculate the significance values (23) and a p value threshold of 0.05 . The basic rank criterion considered was the impact factor. The impact factor considers the number of significantly different expressed genes, normalized fold change 

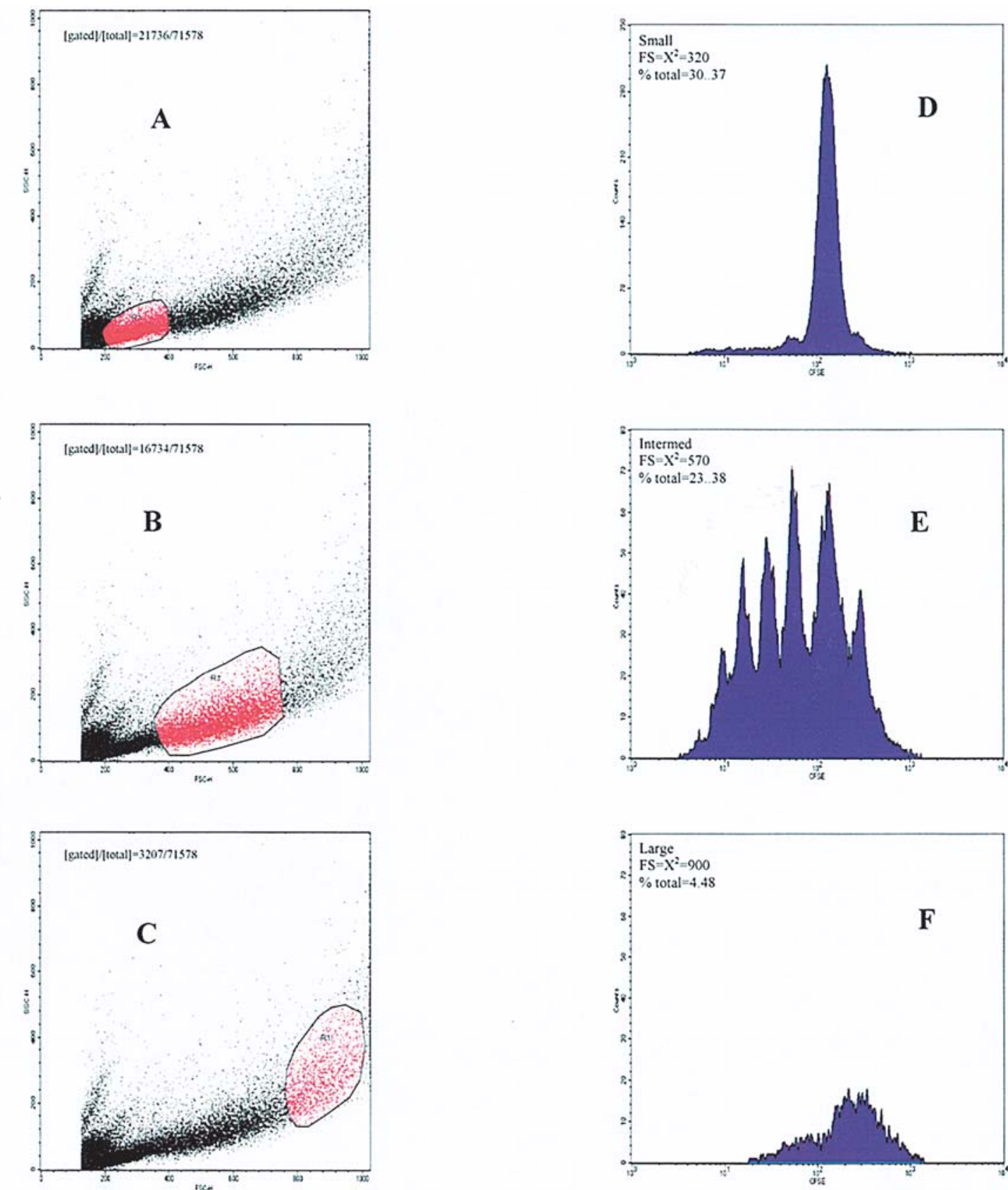

Figure 1. (A-C) Histogram of distribution of lymphocyte population according to their size four days after PHA stimulation. Patterns of cell division in T lymphocytes of small (D), intermediate (E) and large (F) size. Of note, the small, intermediate and large size T cells represented $30.36 \%, 23.37 \%$ and $4.48 \%$ of the total gated cells respectively.

of the genes and their perturbation factors on the pathway, which 'reflect the relative importance of each differentially regulated gene'.

\section{Results}

Mitogen stimulation induced different rates of division of cells of different sizes. CFSE as a fluorescent dye binds to DNA and is diluted through cell divisions. Fig. 1 shows that the majority of cells of small size divided few times. The majority of cells (>90\%) accumulated in one large peak corresponding to a strong CFSE signal corresponding to cells, which did not divide or divided only once. The small population of large size cells divided less than cells of intermediate size. It is possible that most of the cells were in interphase. In contrast, the intermediate size cells formed six clearly distinguished peaks of fluorescence. This indicates that one parental population divided at least five times during four days. Therefore cells for microarray analysis were isolated from the intermediate size population. PHA is a $\mathrm{T}$ cell only mitogen. The small size cells are B-cells, which did not divide.

Following cell division, each daughter cell retains onehalf of the fluorescence of the mother cell. This is illustrated by the well-defined peaks of fluorescence. Each well-defined peak of fluorescence with the mean fluorescence intensity (MFI) of 1/2,1/4, 1/8, 1/16 etc. of the MFI of undivided cells corresponded to $\mathrm{T}$ cells which divided $1,2,3$ and 4 times respectively. Cells which divided $0,1,2,3$ and 4 times were 
Table I. Genes of increased expression level between generation 1 divided and undivided T cells. ${ }^{a}$

\begin{tabular}{|c|c|c|c|}
\hline $\begin{array}{l}\text { Fold } \\
\text { increase }\end{array}$ & Accession & Symbol & Gene name \\
\hline 25.17 & NM_053056 & CCND1 & cyclin D1 (PRAD1: parathyroid adenomatosis 1) \\
\hline 18.40 & AB067516 & KIAA1929 & KIAA1929 protein \\
\hline 15.58 & NM_002090 & GRO3 & GRO3 oncogene \\
\hline 14.83 & NM_003118 & SPARC & secreted protein, acidic, cysteine-rich (osteonectin) \\
\hline 14.05 & NM_002019 & FLT1 & $\begin{array}{l}\text { fms-related tyrosine kinase } 1 \text { (vascular endothelial growth factor/vascular permeability } \\
\text { factor receptor) }\end{array}$ \\
\hline 13.46 & NM_005093 & CBFA2T2 & core-binding factor, runt domain, $\alpha$ subunit $2 ;$ translocated to, 2 \\
\hline 12.98 & NM_015841 & ADAR & adenosine deaminase, RNA-specific \\
\hline 12.79 & NM_001191 & BCL2L1 & BCL2-like 1 \\
\hline 12.06 & NM_005435 & ARHGEF5 & Rho guanine nucleotide exchange factor (GEF) 5 \\
\hline 11.94 & NM_002460 & IRF4 & interferon regulatory factor 4 \\
\hline 11.23 & X65551 & MKI67 & antigen identified by monoclonal antibody Ki-67 \\
\hline 10.70 & NM_001826 & CKS1 & CDC28 protein kinase 1 \\
\hline 10.66 & NM_001566 & INPP4A & inositol polyphosphate-4-phosphatase, type I, $107 \mathrm{kD}$ \\
\hline 10.66 & NM_000213 & ITGB4 & integrin, $\beta 4$ \\
\hline 10.50 & NM_002593 & PCOLCE & procollagen C-endopeptidase enhancer \\
\hline 10.40 & NM_003726 & SCAP1 & src family associated phosphoprotein 1 \\
\hline 10.09 & NM_002734 & PRKAR1A & protein kinase, cAMP-dependent, regulatory, type I, $\alpha$ (tissue specific extinguisher 1 ) \\
\hline 9.70 & NM_002886 & RAP2B & RAP2B, member of RAS oncogene family \\
\hline 9.56 & L12146 & PPP2R3 & $\begin{array}{l}\text { protein phosphatase } 2 \text { (formerly } 2 A \text { ), regulatory subunit } B " \text { (PR 72), } \alpha \text { isoform and (PR 130), } \\
\beta \text { isoform }\end{array}$ \\
\hline 9.44 & AL022069 & RPS6KA2 & ribosomal protein S6 kinase, $90 \mathrm{kD}$, polypeptide 2 \\
\hline 9.37 & NM_005197 & CHES1 & checkpoint suppressor 1 \\
\hline 9.23 & NM_005236 & ERCC4 & excision repair cross-complementing rodent repair deficiency, complementation group 4 \\
\hline 8.96 & NM_002131 & HMGIY & high-mobility group (nonhistone chromosomal) protein isoforms I and Y \\
\hline 8.87 & X59869 & TCF7 & transcription factor 7 (T-cell specific, HMG-box) \\
\hline 8.74 & NM_000136 & FANCC & Fanconi anemia, complementation group $\mathrm{C}$ \\
\hline 8.72 & NM_002732 & PRKACG & protein kinase, cAMP-dependent, catalytic, $\gamma$ \\
\hline 8.52 & NM_003392 & WNT5A & wingless-type MMTV integration site family, member $5 \mathrm{~A}$ \\
\hline 8.27 & NM_000875 & IGF1R & insulin-like growth factor 1 receptor \\
\hline 8.13 & NM_005207 & CRKL & v-crk sarcoma virus CT10 oncogene homolog (avian)-like \\
\hline 8.11 & NM_001530 & HIF1A & hypoxia-inducible factor $1, \alpha$ subunit (basic helix-loop-helix transcription factor) \\
\hline 8.09 & NM_000323 & RET & $\begin{array}{l}\text { ret proto-oncogene (multiple endocrine neoplasia and medullary thyroid carcinoma } 1 \text {, } \\
\text { Hirschsprung disease) }\end{array}$ \\
\hline 8.01 & NM_002253 & KDR & kinase insert domain receptor (a type III receptor tyrosine kinase) \\
\hline 7.72 & NM_000597 & IGFBP2 & insulin-like growth factor binding protein $2(36 \mathrm{kD})$ \\
\hline 7.71 & NM_002311 & LIG3 & ligase III, DNA, ATP-dependent \\
\hline 7.57 & NM_005225 & E2F1 & E2F transcription factor 1 \\
\hline 7.56 & NM_000633 & BCL2 & B-cell CLL/lymphoma 2 \\
\hline 7.55 & NM_001973 & ELK4 & ELK4, ETS-domain protein (SRF accessory protein 1) \\
\hline 7.47 & NM_001423 & EMP1 & epithelial membrane protein 1 \\
\hline 7.29 & $\mathrm{~J} 04102$ & ETS2 & v-ets erythroblastosis virus E26 oncogene homolog 2 (avian) \\
\hline 7.26 & NM_000214 & JAG1 & jagged 1 (Alagille syndrome) \\
\hline 7.22 & NM_004375 & COX11 & COX11 homolog, cytochrome c oxidase assembly protein (yeast) \\
\hline 7.20 & NM_003929 & RAB7L1 & RAB7, member RAS oncogene family-like 1 \\
\hline 7.19 & M12783 & PDGFB & platelet-derived growth factor $\beta$ polypeptide [simian sarcoma viral (v-sis) oncogene homolog] \\
\hline 7.17 & NM_003455 & ZNF202 & zinc finger protein 202 \\
\hline 7.13 & NM_001224 & CASP2 & $\begin{array}{l}\text { caspase } 2 \text {, apoptosis-related cysteine protease (neural precursor cell expressed, } \\
\text { developmentally down-regulated } 2 \text { ) }\end{array}$ \\
\hline 7.06 & NM_005180 & BMI1 & B lymphoma Mo-MLV insertion region (mouse) \\
\hline 7.06 & D11327 & PTPN7 & protein tyrosine phosphatase, non-receptor type 7 \\
\hline 7.02 & NM_005582 & LY64 & lymphocyte antigen 64 homolog, radioprotective $105 \mathrm{kD}$ (mouse) \\
\hline 6.93 & NM_003426 & ZNF74 & zinc finger protein 74 (Cos52) \\
\hline 6.74 & NM_003443 & ZNF151 & zinc finger protein $151(\mathrm{pHZ}-67)$ \\
\hline
\end{tabular}

${ }^{\text {aW }}$ We first determined the $\mathrm{Cy} 3$ to $\mathrm{Cy} 5$ ratio for each microarray spot. Ratios $>6.7$ were considered significant. Details in Materials and methods. 
Table II. Genes of decreased expression level between generation 1 divided and undivided T cells. ${ }^{\text {a }}$

\begin{tabular}{|c|c|c|c|}
\hline $\begin{array}{l}\text { Fold } \\
\text { increase }\end{array}$ & Accession & Symbol & Gene name \\
\hline 0.05 & X07109 & PRKCB1 & protein kinase $C, \beta 1$ \\
\hline 0.06 & NM_002488 & NDUFA2 & NADH dehydrogenase (ubiquinone) $1 \alpha$ subcomplex, $2(8 \mathrm{kD}, \mathrm{B} 8)$ \\
\hline 0.06 & NM_005252 & FOS & v-fos FBJ murine osteosarcoma viral oncogene homolog \\
\hline 0.06 & NM_004276 & CABP1 & calcium binding protein 1 (calbrain) \\
\hline 0.07 & NM_002716 & PPP2R1B & protein phosphatase 2 (formerly $2 \mathrm{~A}$ ), regulatory subunit $\mathrm{A}$ (PR 65 ), $B$ isoform \\
\hline 0.07 & NM_021574 & BCR & breakpoint cluster region \\
\hline 0.07 & NM_001732 & BTN1A1 & butyrophilin, subfamily 1 , member A1 \\
\hline 0.08 & NM_002110 & HCK & hemopoietic cell kinase \\
\hline 0.09 & NM_001188 & BAK1 & BCL2-antagonist/killer 1 \\
\hline 0.09 & NM_009588 & LTB & lymphotoxin B (TNF superfamily, member 3) \\
\hline 0.09 & NM_006259 & PRKG2 & protein kinase, cGMP-dependent, type II \\
\hline 0.09 & NM_005252 & FOS & v-fos FBJ murine osteosarcoma viral oncogene homolog \\
\hline 0.10 & D10202 & PTAFR & platelet-activating factor receptor \\
\hline 0.10 & NM_005433 & YES1 & v-yes-1 Yamaguchi sarcoma viral oncogene homolog 1 \\
\hline 0.10 & NM_000022 & ADA & adenosine deaminase \\
\hline 0.10 & M68520 & CDK2 & cyclin-dependent kinase 2 \\
\hline 0.11 & NM_000887 & ITGAX & integrin, $\alpha \mathrm{X}$ (antigen CD11C (p150), $\alpha$ polypeptide) \\
\hline 0.11 & NM_002359 & MAFG & v-maf musculoaponeurotic fibrosarcoma oncogene homolog G (avian) \\
\hline 0.11 & NM_005694 & COX17 & COX17 homolog, cytochrome c oxidase assembly protein (yeast) \\
\hline 0.11 & NM_005171 & ATF1 & activating transcription factor 1 \\
\hline 0.11 & NM_080549 & PTPN6 & protein tyrosine phosphatase, non-receptor type 6 \\
\hline 0.12 & NM_002422 & MMP3 & matrix metalloproteinase 3 (stromelysin 1 , progelatinase) \\
\hline 0.12 & NM_003032 & SIAT1 & sialyltransferase 1 ( $\beta$-galactoside $\alpha-2,6$-sialytransferase) \\
\hline 0.13 & Z11695 & MAPK1 & mitogen-activated protein kinase 1 \\
\hline 0.13 & AF047182 & NDUFA6 & NADH dehydrogenase (ubiquinone) $1 \alpha$ subcomplex, 6 (14 kD, B14) \\
\hline 0.13 & M31523 & TCF3 & transcription factor 3 (E2A immunoglobulin enhancer binding factors E12/E47) \\
\hline 0.13 & NM_000655 & SELL & selectin L (lymphocyte adhesion molecule 1) \\
\hline 0.13 & NM_005175 & ATP5G1 & $\begin{array}{l}\text { ATP synthase, } \mathrm{H}^{+} \text {transporting, mitochondrial F0 complex, subunit c (subunit 9), } \\
\text { isoform } 1\end{array}$ \\
\hline 0.13 & NM_003441 & ZNF141 & zinc finger protein 141 (clone pHZ-44) \\
\hline 0.14 & NM_004757 & SCYE1 & small inducible cytokine subfamily E, member 1 (endothelial monocyte-activating) \\
\hline 0.14 & NM_002228 & JUN & v-jun sarcoma virus 17 oncogene homolog (avian) \\
\hline 0.14 & NM_001436 & FBL & fibrillarin \\
\hline 0.14 & NM_005394 & PMS2L8 & postmeiotic segregation increased 2-like 8 \\
\hline 0.15 & U47077 & PRKDC & protein kinase, DNA-activated, catalytic polypeptide \\
\hline 0.15 & NM_006243 & PPP2R5A & protein phosphatase 2 , regulatory subunit B (B56), $\alpha$ isoform \\
\hline 0.15 & NM_000038 & APC & adenomatosis polyposis coli \\
\hline 0.16 & NM_013387 & HSPC051 & ubiquinol-cytochrome c reductase complex (7.2 kD) \\
\hline 0.16 & NM_003248 & THBS4 & thrombospondin 4 \\
\hline 0.16 & NM_003326 & TNFSF4 & $\begin{array}{l}\text { tumor necrosis factor (ligand) superfamily, member } 4 \text { (tax-transcriptionally activated } \\
\text { glycoprotein } 1,34 \mathrm{kD} \text { ) }\end{array}$ \\
\hline 0.16 & NM_001618 & ADPRT & ADP-ribosyltransferase [NAD+; poly (ADP-ribose) polymerase] \\
\hline 0.16 & NM_006435 & IFITM2 & interferon induced transmembrane protein $2(1-8 \mathrm{D})$ \\
\hline 0.16 & NM_000448 & RAG1 & recombination activating gene 1 \\
\hline 0.16 & NM_000655 & SELL & selectin L (lymphocyte adhesion molecule 1) \\
\hline 0.17 & NM_032996 & CASP9 & caspase 9 , apoptosis-related cysteine protease \\
\hline 0.17 & NM_003869 & CES2 & carboxylesterase 2 (intestine, liver) \\
\hline 0.17 & M19961 & COX5B & cytochrome c oxidase subunit $\mathrm{Vb}$ \\
\hline 0.17 & NM_001987 & ETV6 & ets variant gene 6 (TEL oncogene) \\
\hline 0.17 & NM_001350 & DAXX & death-associated protein 6 \\
\hline 0.17 & NM_005003 & NDUFAB 1 & NADH dehydrogenase (ubiquinone) $1, \alpha / \beta$ subcomplex, 1 (8 kD, SDAP) \\
\hline 0.17 & NM_006286 & TFDP2 & transcription factor Dp-2 (E2F dimerization partner 2) \\
\hline
\end{tabular}

${ }^{a}$ We first determined the Cy3 to Cy5 ratio for each microarray spot. Ratios $<0.17$ were considered significant. Details in Materials and methods. 

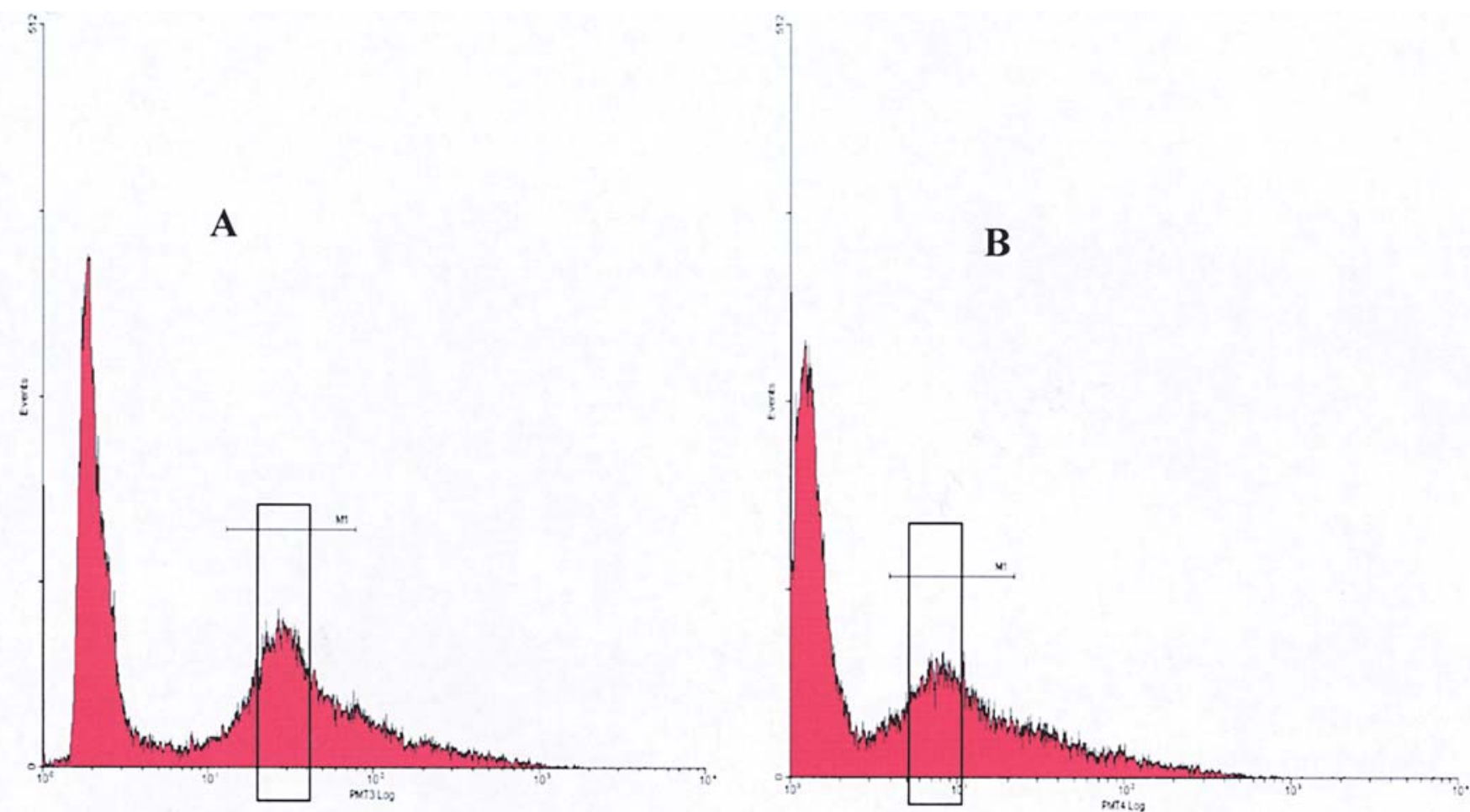

Figure 2. Isolated T lymphocytes were sorted based on the intensity of fluorescence CFSE-label. The gate indicates that cells were isolated only from the peak area corresponding to division 3 (A) and division 4 (B).

A.

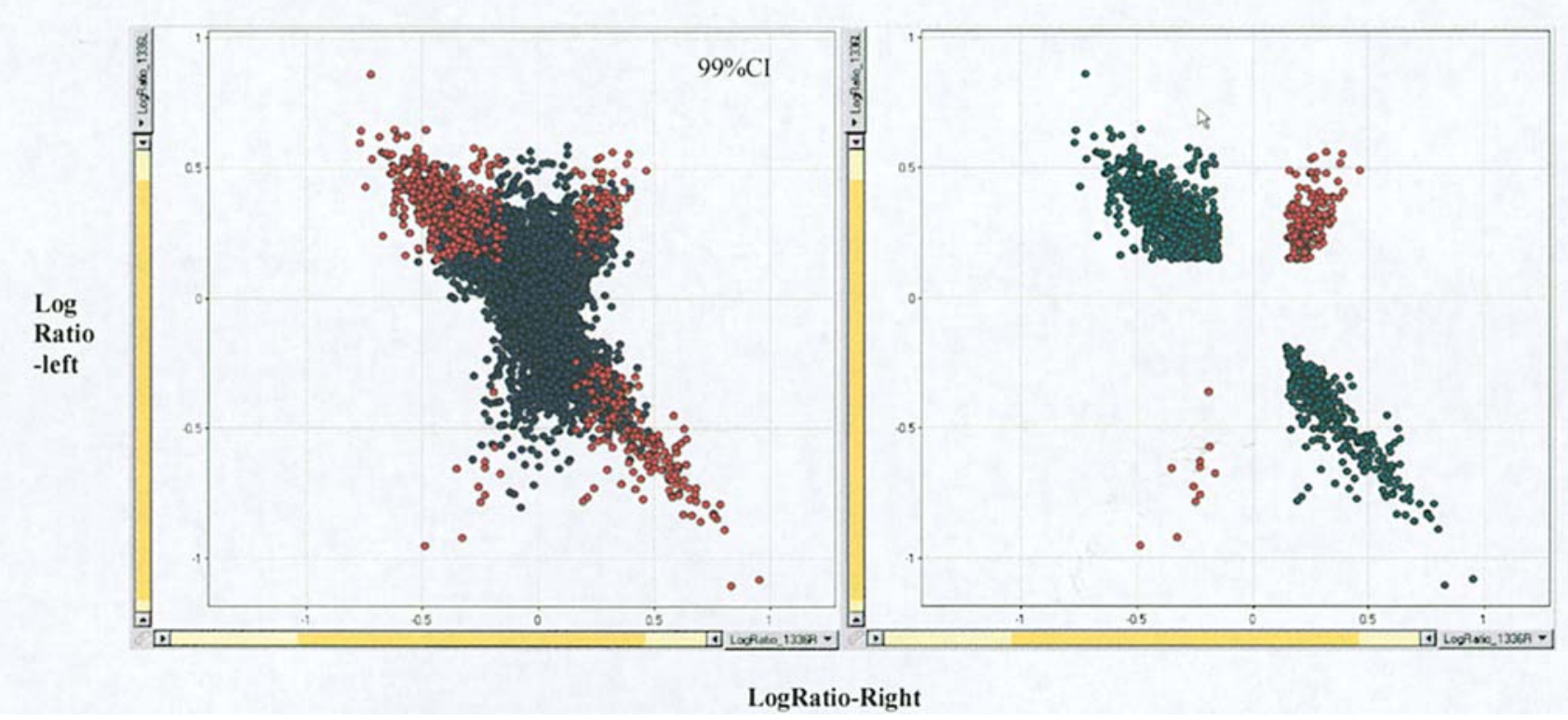

Figure 3. Differently expressed genes between generation 4 and $3 \mathrm{~T}$ cells were identified by microarray. (A) Comparisons of gene expression levels between two generations of $\mathrm{T}$ cells are depicted based on dye-swap hybridization assays. (B) Differently expressed genes (green in B) were identified by removing unchanged genes (blue in A) and discordant genes (red in B).

gated according to the position of the peaks and separated by sorting in cells in division $0,1,3$ and 4 , respectively. Cells in division 2 were not selected to avoid contamination of cells in division 1 and 3 . For cell sorting gates were placed in the middle of the peak to avoid contamination (Fig. 2). The sorted cells were collected for RNA extraction and microarray analysis. This approach allowed the analysis of cells of similar size and metabolism, distinguished between divided cells and avoided contamination by mRNA from other cells (B-cells). The intermediate size cells represented $23.88 \%$ of the total; the small size cells represented $30.37 \%$ of the total, while the large-size cells represented $4.5 \%$ of total cells. 
Table III. Genes of increased expression between T cells divided 4 times and 3 times.

\begin{tabular}{|c|c|c|c|}
\hline unigene_code & Gene name & Fold increase & $\mathrm{p}$ value \\
\hline Hs. 182825 & ribosomal protein L35 & 4.44 & $5.01 \mathrm{E}-17$ \\
\hline Hs.914 & major histocompatibility complex, class II, DP $\alpha 1$ & 4.41 & $1.71 \mathrm{E}-10$ \\
\hline Hs.76038 & isopentenyl-diphosphate $\delta$ isomerase & 4.20 & $3.91 \mathrm{E}-07$ \\
\hline Hs. 181125 & immunoglobulin $\lambda$ locus & 4.15 & $2.86 \mathrm{E}-11$ \\
\hline Hs.100431 & $\begin{array}{l}\text { small inducible cytokine B subfamily (Cys-X-Cys motif), member } 13 \text { (B-cell } \\
\text { chemoattractant) }\end{array}$ & 4.08 & $2.45 \mathrm{E}-14$ \\
\hline Hs.165590 & ribosomal protein $\mathrm{S} 13$ & 3.76 & $3.29 \mathrm{E}-15$ \\
\hline Hs.166468 & programmed cell death 5 & 3.69 & $8.75 \mathrm{E}-15$ \\
\hline Hs.179779 & ribosomal protein L37 & 3.66 & $7.08 \mathrm{E}-15$ \\
\hline Hs.9963 & TYRO protein tyrosine kinase binding protein & 3.64 & $2.40 \mathrm{E}-13$ \\
\hline Hs. 180255 & major histocompatibility complex, class II, DR $\beta 1$ & 3.64 & 4.59E-11 \\
\hline Hs.227751 & lectin, galactoside-binding, soluble, 1 (galectin 1) & 3.62 & 3.35E-09 \\
\hline Hs.181366 & major histocompatibility complex, class II, DR $\beta 5$ & 3.61 & $2.34 \mathrm{E}-14$ \\
\hline Hs.239176 & insulin-like growth factor 1 receptor & 3.53 & $3.57 \mathrm{E}-14$ \\
\hline Hs.119324 & kinesin-like 4 & 3.48 & $1.70 \mathrm{E}-10$ \\
\hline Hs.1051 & granzyme B (granzyme 2, cytotoxic T-lymphocyte-associated serine esterase 1) & 3.46 & $5.80 \mathrm{E}-11$ \\
\hline Hs.8372 & ubiquinol-cytochrome c reductase $(6.4 \mathrm{kD})$ subunit & 3.41 & 7.87E-10 \\
\hline Hs.156110 & immunoglobulin $\kappa$ constant & 3.40 & $1.63 \mathrm{E}-11$ \\
\hline Hs.1499 & heat shock transcription factor 1 & 3.35 & $6.94 \mathrm{E}-12$ \\
\hline Hs.3709 & low molecular mass ubiquinone-binding protein $(9.5 \mathrm{kD})$ & 3.34 & $1.56 \mathrm{E}-13$ \\
\hline Hs.75538 & ribosomal protein $\mathrm{S} 7$ & 3.28 & $1.58 \mathrm{E}-13$ \\
\hline Hs.3066 & granzyme K (serine protease, granzyme 3; tryptase II) & 3.27 & $1.44 \mathrm{E}-09$ \\
\hline Hs.82202 & ribosomal protein L17 & 3.27 & $2.13 \mathrm{E}-13$ \\
\hline Hs.83753 & small nuclear ribonucleoprotein polypeptides B and B1 & 3.26 & $9.09 \mathrm{E}-13$ \\
\hline Hs.174131 & ribosomal protein L6 & 3.25 & $2.44 \mathrm{E}-13$ \\
\hline Hs.112058 & CD27-binding (Siva) protein & 3.25 & $3.61 \mathrm{E}-11$ \\
\hline Hs.44532 & diubiquitin & 3.24 & 4.72E-06 \\
\hline Hs.74407 & nucleolar protein p40; homolog of yeast EBNA1-binding protein & 3.24 & $3.77 \mathrm{E}-13$ \\
\hline Hs.75659 & MpV17 transgene, murine homolog, glomerulosclerosis & 3.21 & $1.50 \mathrm{E}-03$ \\
\hline Hs.23044 & RAD51 (S. cerevisiae) homolog (E coli RecA homolog) & 3.21 & $1.73 \mathrm{E}-11$ \\
\hline Hs.184693 & transcription elongation factor B (SIII), polypeptide $1(15 \mathrm{kD}$, elongin $\mathrm{C})$ & 3.19 & 4.34E-13 \\
\hline Hs.278613 & interferon, $\alpha$-inducible protein 27 & 3.17 & $6.73 \mathrm{E}-07$ \\
\hline Hs.89529 & aldo-keto reductase family 1, member A1 (aldehyde reductase) & 3.16 & 7.74E-13 \\
\hline Hs.97681 & DNA (cytosine-5-)-methyltransferase 2 & 3.13 & $8.50 \mathrm{E}-13$ \\
\hline Hs. 50842 & interferon-induced protein 35 & 3.12 & $5.07 \mathrm{E}-11$ \\
\hline Hs.695 & cystatin B (stefin B) & 3.09 & $1.19 \mathrm{E}-12$ \\
\hline Hs.226307 & phorbolin (similar to apolipoprotein B mRNA editing protein) & 3.08 & 9.19E-05 \\
\hline Hs.288986 & survival of motor neuron 1 , telomeric & 3.08 & $1.16 \mathrm{E}-12$ \\
\hline Hs.107476 & ATP synthase, $\mathrm{H}^{+}$transporting, mitochondrial F1F0, subunit $\mathrm{g}$ & 3.07 & $2.22 \mathrm{E}-12$ \\
\hline Hs.182241 & interferon induced transmembrane protein $3(1-8 \mathrm{U})$ & 3.07 & $1.67 \mathrm{E}-12$ \\
\hline Hs. 21635 & tubulin, $\gamma 1$ & 3.05 & $5.73 \mathrm{E}-09$ \\
\hline Hs.75596 & interleukin 2 receptor, $\beta$ & 3.04 & $6.96 \mathrm{E}-12$ \\
\hline Hs.146360 & interferon induced transmembrane protein $1(9-27)$ & 3.04 & $1.62 \mathrm{E}-12$ \\
\hline Hs.90443 & $\begin{array}{l}\text { NADH dehydrogenase (ubiquinone) Fe-S protein } 8 \text { ( } 23 \mathrm{kD}) \text { (NADH-coenzyme Q } \\
\text { reductase) }\end{array}$ & 3.01 & $5.71 \mathrm{E}-05$ \\
\hline Hs.1741 & integrin, $\beta 7$ & 3.01 & $2.80 \mathrm{E}-11$ \\
\hline Hs.282997 & glucosidase, $\beta$; acid (includes glucosylceramidase) & 3.00 & $1.46 \mathrm{E}-03$ \\
\hline
\end{tabular}

Differentially expressed genes between pairs of generations of activated T lymphocytes. We found that a number of genes were up- and down-regulated. The magnitude of the transcriptional response was different between activated generation 1 and undivided T cells by PHA (Tables I and II). The significantly different levels of expression of activated genes were defined based on fold increase in the expression levels of the corresponding mRNAs. Because the MDACC chips showed higher 
Table IV. Genes of decreased expression between T cells divided 4 times and 3 times.

\begin{tabular}{|c|c|c|c|}
\hline unigene_code & Gene name & $\begin{array}{c}\text { Fold } \\
\text { increase }\end{array}$ & $\mathrm{p}$ value \\
\hline Hs.180016 & semenogelin II & 0.12 & $2.46 \mathrm{E}-19$ \\
\hline Hs. 1513 & interferon $(\alpha, \beta$ and $\omega)$ receptor 1 & 0.13 & $1.47 \mathrm{E}-20$ \\
\hline Hs.128856 & CSR1 protein & 0.14 & 7.73E-21 \\
\hline Hs.21951 & Homo sapiens Xq pseudoautosomal region; segment 1/2 & 0.15 & $6.35 \mathrm{E}-13$ \\
\hline Hs.86161 & GPI anchored molecule like protein & 0.15 & $2.10 \mathrm{E}-17$ \\
\hline Hs.113262 & 5-hydroxytryptamine (serotonin) receptor 4 & 0.15 & $2.02 \mathrm{E}-10$ \\
\hline Hs.72879 & melanoma antigen, family A, 1 (directs expression of antigen MZ2-E) & 0.15 & $1.00 \mathrm{E}-18$ \\
\hline Hs.200598 & KIAA0537 gene product & 0.16 & $2.18 \mathrm{E}-14$ \\
\hline Hs.263395 & sema domain, transmembrane domain (TM), and cytoplasmic domain, (semaphorin) 6A & 0.16 & $9.21 \mathrm{E}-13$ \\
\hline Hs.170027 & mouse double minute 2 , human homolog of; $\mathrm{p} 53$-binding protein & 0.17 & $1.14 \mathrm{E}-19$ \\
\hline Hs.66744 & twist (Drosophila) homolog (acrocephalosyndactyly 3; Saethre-Chotzen syndrome) & 0.17 & $3.95 \mathrm{E}-19$ \\
\hline Hs.194679 & WNT1 inducible signaling pathway protein 2 & 0.17 & $6.18 \mathrm{E}-19$ \\
\hline Hs.169854 & hypothetical protein SP192 & 0.17 & $1.27 \mathrm{E}-17$ \\
\hline Hs.1827 & nerve growth factor receptor (TNFR superfamily, member 16) & 0.18 & $1.03 \mathrm{E}-17$ \\
\hline Hs.12056 & asialoglycoprotein receptor 1 & 0.19 & $2.11 \mathrm{E}-16$ \\
\hline Hs.2820 & oxytocin receptor & 0.19 & $1.13 \mathrm{E}-18$ \\
\hline Hs.146688 & prostaglandin E synthase & 0.19 & $7.48 \mathrm{E}-19$ \\
\hline Hs.103124 & ATPase, $\mathrm{Ca}^{++}$transporting, plasma membrane 3 & 0.19 & $6.00 \mathrm{E}-12$ \\
\hline Hs.79090 & exportin 1 (CRM1, yeast, homolog) & 0.19 & $1.58 \mathrm{E}-18$ \\
\hline Hs.1985 & spectrin, $\alpha$, erythrocytic 1 (elliptocytosis 2 ) & 0.19 & $1.41 \mathrm{E}-18$ \\
\hline Hs.301174 & glyceraldehyde-3-phosphate dehydrogenase pseudogene 14 & 0.20 & $3.96 \mathrm{E}-18$ \\
\hline Hs.199179 & RAN binding protein 2 & 0.20 & $1.73 \mathrm{E}-13$ \\
\hline Hs.2913 & EphB3 & 0.20 & $1.35 \mathrm{E}-17$ \\
\hline Hs.24979 & hypothetical protein DKFZp761P1010 & 0.21 & $2.72 \mathrm{E}-17$ \\
\hline Hs.6975 & PRO1073 protein & 0.21 & $1.20 \mathrm{E}-17$ \\
\hline Hs.38481 & cyclin-dependent kinase 6 & 0.22 & $2.72 \mathrm{E}-17$ \\
\hline Hs. 256278 & tumor necrosis factor receptor superfamily, member 1B & 0.22 & $4.71 \mathrm{E}-17$ \\
\hline Hs.2958 & RNA binding motif protein, Y chromosome, family 1 , member A1 & 0.22 & $8.20 \mathrm{E}-04$ \\
\hline Hs.115617 & corticotropin releasing hormone-binding protein & 0.22 & $1.04 \mathrm{E}-11$ \\
\hline Hs.159651 & death receptor 6 & 0.22 & $1.55 \mathrm{E}-08$ \\
\hline Hs.104133 & GABAA receptor $\gamma 3$ subunit [human, fetal brain, mRNA Partial, $1536 \mathrm{nt}$ ] & 0.22 & $1.51 \mathrm{E}-14$ \\
\hline Hs.73923 & pancreatic lipase-related protein 1 & 0.22 & $6.31 \mathrm{E}-14$ \\
\hline Hs.41749 & protein kinase, cGMP-dependent, type II & 0.23 & $5.20 \mathrm{E}-05$ \\
\hline Hs.171763 & CD22 antigen & 0.23 & 7.30E-11 \\
\hline Hs.288618 & potassium channel, subfamily $\mathrm{K}$, member 10 & 0.23 & $1.68 \mathrm{E}-15$ \\
\hline Hs.42824 & hypothetical protein FLJ10718 & 0.23 & $1.08 \mathrm{E}-11$ \\
\hline Hs.28505 & ubiquitin-conjugating enzyme E2H (homologous to yeast UBC8) & 0.23 & $3.54 \mathrm{E}-11$ \\
\hline Hs. 47860 & neurotrophic tyrosine kinase, receptor, type 2 & 0.23 & $8.31 \mathrm{E}-05$ \\
\hline Hs.227850 & KIAA0953 protein & 0.24 & $1.88 \mathrm{E}-16$ \\
\hline Hs.106511 & protocadherin 17 & 0.24 & $5.91 \mathrm{E}-06$ \\
\hline
\end{tabular}

activation of transcription, we used the 6.74-fold increase and 0.05 -fold increase as cut-off values. We found 100 activated genes from a total of 1824 genes. Comparison of the transcript levels from cells in the first division and undivided $\mathrm{T}$ cells revealed that genes related with cell cycle and survival were dramatically up-regulated, such as Cyclin D1 (fold increase: 25.17), BCL2L1 (12.79), CDK2 (0.10), BAK1 (0.09), TNFSF4 $(0.16)$. This illustrated that $\mathrm{T}$ cells activate early more genes associated with cell division and survival.
The Agilent chips identified 1325 genes differently expressed in generation 4 compared with generation 3 (Fig. 3 ). To select significantly activated genes, we used a 3 -fold increase and a 20-fold decrease in the amount of transcribed products as cut-off values (Tables III and IV). Up-regulation and down-regulation of gene expression following division indicated that daughter cells expressed higher levels of the genes associated with translation, such as ribosomal proteins. Significant up-regulation of expression of genes involved in 
Table V. Identified gene clusters among differentially expressed genes between dividing T cells.

\begin{tabular}{|c|c|c|c|c|c|}
\hline \multirow[t]{2}{*}{ Gene cluster } & \multirow[b]{2}{*}{ Generations } & \multicolumn{2}{|c|}{ Gene no. } & \multicolumn{2}{|c|}{$\mathrm{p}$ values } \\
\hline & & 1 vs. 0 & 4 vs. 3 & 1 vs. 0 & 4 vs. 3 \\
\hline \multicolumn{6}{|l|}{ Molecular functions } \\
\hline Signal transducer activity & & 23 & 51 & 0.27697 & $0.00071^{\mathrm{a}}$ \\
\hline Receptor activity & & 10 & 28 & 0.17826 & $0.00724^{\mathrm{a}}$ \\
\hline Receptor binding & & 8 & 15 & 0.39455 & $0.00667^{\mathrm{a}}$ \\
\hline Binding & & 78 & 183 & 0.17857 & $0.00038^{\mathrm{a}}$ \\
\hline Nucleotide binding & & 16 & 46 & $0.04962^{\mathrm{a}}$ & 0.33669 \\
\hline Protein binding & & 41 & 72 & $0.04428^{\mathrm{a}}$ & $0.00753^{\mathrm{a}}$ \\
\hline Transcription regulator activity & & 19 & 26 & 0.17176 & 0.06631 \\
\hline Transcription factor activity & & 17 & 19 & 0.06937 & 0.09705 \\
\hline Catalytic activity & & 40 & 114 & 0.38994 & 0.27099 \\
\hline \multicolumn{6}{|l|}{ Biological processes } \\
\hline Physiological process & & 85 & 246 & 0.1954 & $0.00369^{\mathrm{a}}$ \\
\hline Metabolism & & 63 & 166 & 0.4458 & 0.06596 \\
\hline Nucleotide & & - & 64 & - & 0.08620 \\
\hline Intracellular macromolecular & & 32 & 75 & 0.20565 & 0.21987 \\
\hline Cellular process & & 88 & 244 & 0.38518 & $0.00026^{\mathrm{a}}$ \\
\hline Transport & & - & 49 & - & 0.12220 \\
\hline Regulator of cellular metabolism & & - & 34 & - & $0.00481^{\mathrm{a}}$ \\
\hline Cell communication & & 36 & 69 & 0.24474 & $0.00025^{\mathrm{a}}$ \\
\hline Regulation of biological process & & 42 & 60 & 0.30792 & $0.00013^{\mathrm{a}}$ \\
\hline \multicolumn{6}{|l|}{ Cellular components } \\
\hline Cell & & 70 & 227 & 0.17423 & $0.00304^{\mathrm{a}}$ \\
\hline Plasma membrane & & 27 & 45 & 0.46883 & $0.00780^{\mathrm{a}}$ \\
\hline Cytoplasm & & 53 & 88 & 0.37383 & 0.15286 \\
\hline Organelle & & 47 & 138 & 0.49119 & 0.25581 \\
\hline Nucleus & & 35 & 77 & 0.38520 & 0.16987 \\
\hline Endoplasmic reticulum & & 2 & 20 & 0.10683 & 0.09258 \\
\hline Mitochondria & & 11 & 21 & 0.06662 & $0.03276^{\mathrm{a}}$ \\
\hline Protein complex & & 14 & 60 & 0.14193 & $0.01617^{\mathrm{a}}$ \\
\hline Significant $p$ values & & & & $2 / 23$ & $14 / 23$ \\
\hline
\end{tabular}

programmed cell death (PCD5) and cytolysis (granzyme) was also observed.

Mitogen activation induced distinct gene ontology profiles in divided T cells. To ascertain whether the different levels of expression of the gene transcripts associate with the activation of functional genes in specific processes we performed clustering analysis. Table $\mathrm{V}$ shows the gene transcripts expressed in generation 4 versus generation 3: 275 genes were important in molecular function, 183 genes were involved in binding/cell adhesion, and 114 genes were involved in catalytic processes, while 267 genes were involved in biological processes. The results confirmed the activation of translation and of cellular metabolism of later generations of T cells.

Less activated genes were identified by clustering analysis, when generation 1 of divided was compared with undivided $\mathrm{T}$ cells (Table V). Significant differences $(\mathrm{p}<0.05)$ were observed only in genes involved in protein binding and nucleotide synthesis and transport. It is possible that differences resulted from different designs of the chips, i.e. from the different probes in each chip. However it is also possible that stronger specific gene activation occurs in later divisions. Cells which divided once activated a large number of genes although there was less specificity in the activated pathways.

Mitogen stimulation activated different signaling pathways in early-and late-divided cells. To identify the impact of mitogen stimulation in biological processes, the impact factors were determined for each activated pathway.

Between generation 1 and undivided T cells, mitogen stimulation had the strongest impact on the focal adhesion pathway (impact factor 327.39) and the least impact on the cytokine-cytokine receptor interaction pathway (impact factor 68.71). Similar results were obtained with generation 4 and 3 stimulated $\mathrm{T}$ cells (focal adhesion impact factor 34.77 ). The least activated pathway was the Notch signaling (impact factor 
Table VI. Impacted pathways in T lymphocytes by mitogen stimulation identified by the Onto-Pathway Express program.

\begin{tabular}{|c|c|c|c|c|c|c|}
\hline \multirow[t]{2}{*}{ Pathways } & \multicolumn{2}{|c|}{ Impact factor } & \multicolumn{2}{|c|}{ p-value } & \multicolumn{2}{|c|}{ Input/pathway } \\
\hline & 1 vs. 0 & 4 vs. 3 & 1 vs. 0 & 4 vs. 3 & 1 vs. 0 & 4 vs. 3 \\
\hline Focal adhesion & 327.39 & 34.77 & $6.5052 \mathrm{E}-2$ & $1.2891 \mathrm{E}-1$ & $10 / 163$ & $5 / 163$ \\
\hline Regulation of actin-cytoskeleton & 166.01 & 34.11 & $3.0062 \mathrm{E}-1$ & $3.5965 \mathrm{E}-1$ & $6 / 209$ & $5 / 209$ \\
\hline Cytokine-cytokine receptor interaction & 68.71 & 27.06 & $2.5202 \mathrm{E}-1$ & $4.9285 \mathrm{E}-1$ & $6 / 258$ & $10 / 258$ \\
\hline TGF- $\beta$ signaling & - & 23.76 & - & $2.1907 \mathrm{E}-1$ & - & $3 / 83$ \\
\hline Jak-STAT signaling & - & 14.44 & - & $1.8960 \mathrm{E}-1$ & - & $5 / 159$ \\
\hline MAPK signaling & 127.20 & 12.37 & $8.7642 \mathrm{E}-2$ & $9.2687 \mathrm{E}-2$ & $12 / 247$ & $3 / 247$ \\
\hline Cell cycle & - & 11.22 & - & $3.1436 \mathrm{E}-1$ & - & $3 / 98$ \\
\hline Phosphatidylinositol signaling & 184.49 & - & 3.4935E-1 & - & $2 / 69$ & - \\
\hline Wnt signaling & 123.39 & - & $3.3275 \mathrm{E}-3$ & - & $8 / 146$ & - \\
\hline Apoptosis & 70.09 & - & $1.4254 \mathrm{E}-1$ & - & $5 / 98$ & - \\
\hline
\end{tabular}

Table VII. Impacted focal adherent pathway components in T lymphocytes by mitogen stimulation

\begin{tabular}{llc}
\hline Generation & \multicolumn{1}{c}{ Component } & $\begin{array}{c}\text { Fold } \\
\text { increase }\end{array}$ \\
& & 3.01 \\
\hline 4 vs. 3 & Integrin B-chain (ITGB) & 2.01 \\
& VAV & 1.93 \\
& Integrin-linked kinases (ILK) & 0.45 \\
& Caveolin (CAV) & 0.58 \\
& Filamin & 25.17 \\
1 vs. 0 & Cyclin D1 (CycD) & 14.05 \\
& FMS-like tyrosine kinase 1 (FLT1) & 10.66 \\
& Integrin ß-chain (ITGB) & 8.27 \\
& Insulin-like growth factor type 1 & \\
& receptor (IGF1R) & 8.01 \\
& Kinase insert domain receptor (KDR) & 7.56 \\
& B-cell CLL/lymphoma 2 (Bcl-2) & 7.19 \\
& Platelet-derived growth factor ß & \\
(PDGFB) & 0.05 \\
Protein kinase C (PKC) & 0.13 \\
Mitogen-activated protein kinase & \\
(MAPK) & 0.14 \\
c-JUN & \\
\hline
\end{tabular}

3.15) (Table VI). Therefore although we used different chips, the increase in the impact factor was similar between the least affected and the most affected pathway (5.22- vs. 10.9-fold.)

The focal adhesion (FA) pathway is an example of precise and efficient coordination of signaling events (24), which connects the extracellular environment with intracellular signaling and protein function. Connection is made through transmembrane integrin-receptors and cytoskeletal components. Different conditions of ECM, of type of integrin, and of cellular environment result in different responses of the FA. The focal adhesion kinase (FAK) and paxillin are the main components of focal adhesion complex, induced by Rho (Ras homolog)family members Fac and CDC42. Integrin signaling uses as a second intracellular messenger system tyrosine and serine/ threonine kinases, and corresponding phosphatases. This pathway signals bi-directionally $(25,26)$.

Between generation 1 and undivided T cells, the MAPK signaling pathway had the most activated genes (12 genes compared with 10 genes of the focal adhesion pathway). Ten genes were found in the focal adhesion pathway as differentially expressed, either up- or down-regulated (Table VII). They included CyclinD1, ITGB, Bcl-2, PKC, MAPK, and c-JUN. Cyclin D is the cell cycle protein. Bcl-2 and Bcl-xL are the main pro-survival molecules, which are activated after mitogen, antigen and/or cytokine activation of lymphcytes. c-Jun can bind DNA and regulate transcription. It is also notable that the anti-apoptotic pathway is strongly activated, showing that early generations of divided $\mathrm{T}$ cells have better survival ability than the later generations.

It is interesting that JAK-STAT and TGF- $\beta$ signaling pathway are found to be activated when comparing generations 4 and 3. The comparison also indicated that the cytokinecytokine receptor interaction pathway had the most affected genes. Therefore the least activated pathway in division $1 \mathrm{had}$ the most activated genes in division 4 . There were 10 genes activated in this pathway compared with 5 genes activated in the focal adhesion pathway. Activated genes of the focal adhesion pathway consisted of integrin B-chain (ITGB), filamin, integrin-linked kinases (ILK), VAV, and Caveolin.

Filamin belongs to the transmembrane integrin family, involved in ECM signaling (27). ITGB mediates various interactions. Localization of ITGB isoforms affects myotubule morphology and myogenesis. Tyrosine-phosphorylated caveolin can interact with FA proteins by FAK, affecting cell motility and directional control (28). Intracellular serine/ threonine integrin-linked kinases (ILK) are one of the convergence points of integrin- and growth factor-signaling pathways. The small adaptor protein, vav, couples tyrosine kinase signals with the activation of the Rho/rac GTPases, thus leading to cell differentiation and/or proliferation.

Therefore the activated genes were different in the cells which divided once compared with cells which divided 4 times. The results indicate that the identification of the affected pathway is not sufficient for definition of a $\mathrm{T}$ cell response, but all factors should be considered in defining a global response to activation (Table VII). 
Therefore responses at the first division consisted of activation of the genes controlling adhesion, cell division, and responses to extracellular signals, while responses at the fourth division consisted of activation of cytokine receptor signaling as we expected.

\section{Discussion}

We identified novel differences in gene expression profiles from divided generation 1 compared with undivided and from generation 4 compared with generation 3 , of $\mathrm{T}$ lymphocytes. The transcription profiles of generation 0 and $1 \mathrm{~T}$ cells have more genes activated in surviving and proliferation, while generation 4 and $3 \mathrm{~T}$ cells have more in cytokine signaling and cell function. We identified activated gene pathways, which are affected quantitatively and qualitatively when $T$ cells are activated by mitogen. In both generations of $\mathrm{T}$ cells, the FA pathway is the most activated, while early generations of $\mathrm{T}$ cells have activated survival pathways and later generations of $\mathrm{T}$ cells have activated JAK-STAT and TGF- $B$ signaling pathway. Our results together define functional 'signatures' of responses to PHA and indicate that a cancer immunogen should activate $\mathrm{T}$ cells to divide at least 4 times to expect any effector cytokine secretion.

Mitogen activated a number of genes related to signal transduction and gene transcription (Table V). These genes, especially the pathway related genes (Table VII), connected membrane binding, signal transduction, and metabolism. Modulation of transcription of gene expression of $\mathrm{T}$ cells during differentiation of effector cells was reported. Of these, transcripts encoding for CD62L, GPI-linked proteins, chemokines CCR2 and CCR5, perforin, granzyme, TCR signaling, and cytokine signaling proteins had increased expression in effector T cells. However, the conclusions of this study were obtained by comparing murine $\mathrm{CD} 8^{+} \mathrm{T}$ cells 8 days after stimulation of naïve and unstimulated T cells (29). Hess et al (14) recently reported the kinetic profiles of gene expression of naïve $\mathrm{CD}^{+} \mathrm{T}$ cells after activation. Upon anti-CD3 and anti-CD28 antibody stimulation, human naïve $\mathrm{CD}^{+} \mathrm{T}$ cells had 196 genes with changed expression levels during the first $24 \mathrm{~h}$. The genes were functionally involved in maintenance of rest status, adhesion/migration, cell cycle progression, and cytokine production. Chtanova (15) reported genes preferentially transcribed by T cells. These genes provided 'signatures' for $\mathrm{T}$ cell responses. For example, they differentiated $\gamma \delta \mathrm{T}$ cells from $\alpha \beta \mathrm{T}$ cells by a number of genes down-regulated during activation, including genes involved in the pre-mRNA splicing process, such as transformer $2 \beta$, suppressor of white apricot homologous 2, and pre-mRNA splicing factor 16. Mao et al (30) used PHA-stimulated lymphocytes in the presence of IL-2 to identify unknown genes and to associate them to biological processes. To identify genes specific for $\mathrm{T}$ cell activation, the authors examined genes co-regulated with IL-2. They found some ESTs (expressed sequence tags) that encoded previously unknown proteins involved in GTP metabolism, while others were linked to newly published cDNAs and cytokine receptor genes. In support of our conclusions, the authors found that genome scale analysis of gene transcription during $\mathrm{T}$ cell activation can facilitate the identification of genetic functional networks. Adarichev et al created the portrait of experimental autoimmune arthritis (31) using the same algorithm for the functional classification of genes. The authors found similar gene clusters to those in the current study. The main gene clusters were related to chemokine, cytokine, activation, inflammation and cell adhesion.

Compared with the previous studies our contribution was to connect the differentially expressed genes into a logical biological scenario. Our results refine the definition of activated $\mathrm{T}$ cells specifically to adjacent generation (pair generations), revealing that at the level of mRNA transcription, the metabolism of cellular components and special characteristics were changed.

The significant change between adjacent generations of T lymphocytes in our study (Table VII) showed that early generation activated $\mathrm{T}$ cells are resistant to apoptosis, sensitive to growth stimulation and proliferate well, as shown by the expression levels of growth factor related, Cyclin-D1 and Bcl-2. The large number of activated genes of MAPK pathway, 12 in early generations versus 3 in later generations (Table VI), indicate the rapid and dramatic response of $\mathrm{T}$ cells to external stimuli. After the quick expansion, the later generations of T cells (generation 4) decrease their responses to ECM signals while increasing the motility and proliferation ability of daughter cells.

This phenomenon is interpreted as daughter T lymphocytes being well prepared to respond by effector-function when they meet a target, while rejecting other activators, e.g. Notchligands, through decreased sensitivity.

Our conclusions are supported by the activation of naïve T cells. Stimulation of TCR and of co-stimulatory molecules regulates serial transcription of genes such as those involved in the cell cycle, cytokine production and survival (29,32-34).

Global gene transcription profiling based on the relationship between effector molecule-expression and the number of divisions has important implications for development of cancer vaccines and prediction of the effectiveness of vaccineactivated lymphocytes associated with tumors. T cells isolated from freshly-resected tumors can proliferate in the presence of small amounts of cytokines. Cytokines induce proliferation of antigen-activated T cells ex vivo. Analysis of the transcriptional profile of cytokine, e.g. IL-2, IL-15 or IL-7propagated $\mathrm{T}$ cells, undergoing several divisions can be compared with the transcriptional profile of $\mathrm{T}$ cells to a standard mitogen, and to several antigens which can prime or re-activate $\mathrm{CD}^{+}$cell proliferation in vitro. Based on this scenario, an increase in the level of granzyme B or perforin, for example, after activation with IL-2 will indicate that ex vivo activated cells are differentiated and are unlikely to expand more or they are incompletely differentiated and are likely to expand at recall with the same Ag. If the first scenario is found to be correct then it will be necessary to replace the Ag used for vaccination to select a different population of effectors.

Furthermore, the MAPK and PKC pathways are the main effector pathways of TCR-signaling. A number of transcriptional regulators, e.g. Foxp-3, are activated by ERK-signals of insufficient strength. Expression of ERK-targeted genes and of transcriptional regulators by stimulation with a tumor antigen in relation to the 'normal' stimulation levels will predict whether the vaccine will activate anti-tumor effector cells or regulatory cells $\left(\mathrm{T}_{\text {reg }}\right)$ which inhibit the inflammatory responses. 
Global lymphocyte gene transcription profiling should become useful for prediction of cancer progression due to escape from immunosurveillance or establishment of tolerance. In the study of colorectal cancer metastasis, increased mRNA levels of $\mathrm{T}$ cell activation markers in TIL, such as IFN- $\gamma$, granzyme $\mathrm{B}$, and $\mathrm{CD} 45 \mathrm{RO}$, were found in tumor samples and correlated with absence of signs of early metastasis invasion and increased survival (35). Another study of gene profiling in melanoma (36) found 33 genes in the pretreatment samples to be predictive of clinical response. Of these 16 out of 33 genes were related to $\mathrm{T}$ cell activation, including CTL-mediated cytolysis, TGF-3/IFN/TNF regulation, JAK/STAT pathway, as is described in the current study. For example, the expression level of INF- $\gamma$ regulatory factor 2 (IRF2) was enhanced and IFN- $\alpha$ inducible protein 27 (IFI27) suppressed in pretreated samples that regressed completely compared with those of nonresponding patients. However, in the current study, IRF2 was up-regulated 1.2-fold and IFI27 3.2-fold in generation 4 $\mathrm{T}$ cells.

Our findings define a 'systemic biology approach' for identification of the responsiveness or unresponsiveness to tumor and of the immunogenicity of cancer vaccines. Prior to the easy observation of dramatic changes in surface molecules and effector cytokines, $\mathrm{T}$ cells respond with changes in transcription, translation and adhesion which target specific genes. Such early changes are linked temporally with changes in effector molecules. The detection of early changes in apparently unrelated genes would allow the development of better vaccines for human cancer.

\section{Acknowledgements}

This work was supported in part by an NIH Core grant (no. 16662), DOD grant (no. 01-1-299), and funds from the Graduate School of Biomedical Science and Agilent Technologies, Inc. We thank Dr Scott Vacha (Agilent Technologies, Inc.) for assistance and guidance in microarray analysis.

\section{References}

1. Ioannides CG, Ioannides MG and O'Brian CA: T-cell recognition of oncogene products: a new strategy for immunotherapy. Mol Carcinog 6: 77-82, 1992.

2. Peoples GE, Anderson BW, Lee TV, Murray JL, Kudelka AP, Wharton JT and Ioannides CG: Vaccine implications of folate binding protein, a novel cytotoxic $\mathrm{T}$ lymphocyte-recognized antigen system in epithelial cancers. Clin Cancer Res 5: 4214-4223, 1999.

3. Ioannides CG, Fisk B, Fan D, Biddison WE, Wharton JT and O'Brian CA: Cytotoxic T cells isolated from ovarian malignant ascites recognize a peptide derived from the HER-2/neu protooncogene. Cell Immunol 151: 225-234, 1993.

4. Lee TV, Anderson BW, Peoples GE, Castilleja A, Murray JL, Gershenson DM and Ioannides CG: Identification of activated tumor antigen-reactive $\mathrm{CD} 8^{+}$cells in healthy individuals. Oncol Rep 7: 455-466, 2000.

5. Sotiropoulou PA, Perez SA, Iliopoulou EG, et al: Cytotoxic T-cell precursor frequencies to HER-2 (369-377) in patients with HER-2/neu-positive epithelial tumours. Br J Cancer 89: 1055-1061, 2003.

6. Peoples GE, Gurney JM, Hueman MT, et al: Clinical trial results of a HER2/neu (E75) vaccine to prevent recurrence in high-risk breast cancer patients. J Clin Oncol 23: 7536-7545, 2005.

7. Hueman MT, Dehqanzada ZA, Novak TE, et al: Phase I clinical trial of a HER-2/neu peptide (E75) vaccine for the prevention of prostate-specific antigen recurrence in high-risk prostate cancer patients. Clin Cancer Res 11: 7470-7479, 2005.
8. Grogan JL, Mohrs M, Harmon B, Lacy DA, Sedat JW and Locksley RM: Early transcription and silencing of cytokine genes underlie polarization of $\mathrm{T}$ helper cell subsets. Immunity 14: 205-215, 2001.

9. Marsland BJ, Soos TJ, Spath G, Littman DR and Kopf M: Protein kinase $\mathrm{C}$ theta is critical for the development of in vivo T helper (Th)2 cell but not Th1 cell responses. J Exp Med 200: 181-189, 2004.

10. Murphy KM, Ouyang W, Farrar JD, et al: Signaling and transcription in T helper development. Annu Rev Immunol 18: 451-494, 2000.

11. Kretschmer K, Apostolou I, Hawiger D, Khazaie K, Nussenzweig MC and von Boehmer H: Inducing and expanding regulatory $\mathrm{T}$ cell populations by foreign antigen. Nat Immunol 6: 1219-1227, 2005

12. Veldhoen M, Hocking RJ, Atkins CJ, Locksley RM and Stockinger B: TGFbeta in the context of an inflammatory cytokine milieu supports de novo differentiation of IL-17-producing T cells. Immunity 24: 179-189, 2006

13. Dong C: Diversification of T-helper-cell lineages: finding the family root of IL-17-producing cells. Nat Rev Immunol 6: 329-333, 2006.

14. Hess K, Yang Y, Golech S, Sharov A, Becker KG, and Weng NP: Kinetic assessment of general gene expression changes during human naive CD4+ T cell activation. Int Immunol 16: 1711-1721, 2004.

15. Chtanova T, Newton R, Liu SM, et al: Identification of T cellrestricted genes, and signatures for different $\mathrm{T}$ cell responses, using a comprehensive collection of microarray datasets. J Immunol 175: 7837-7847, 2005.

16. Wang E, Panelli MC and Marincola FM: Gene profiling of immune responses against tumors. Curr Opin Immunol 17: 423-427, 2005.

17. Khatri P, Sellamuthu S, Malhotra P, Amin K, Done A and Draghici S: Recent additions and improvements to the OntoTools. Nucleic Acids Res 33: W762-W765, 2005 (Web Server issue).

18. Kawano K, Efferson CL, Peoples GE, Carter D, Tsuda N, Murray JL and Ioannides CG: Sensitivity of undifferentiated, high-TCR density CD8+ cells to methylene groups appended to tumor antigen determines their differentiation or death. Cancer Res 65: 2930-2937, 2005

19. Choi Y, Shimogawa H, Murakami K, Ramdas L, Zhang W, Qin J and Uesugi M: Chemical genetic identification of the IGF-linked pathway that is mediated by STAT6 and MFP2. Chem Biol 13: 241-249, 2006.

20. Gibson G, Riley-Berger R, Harshman L, Kopp A, Vacha S, Nuzhdin S and Wayne M: Extensive sex-specific nonadditivity of gene expression in Drosophila melanogaster. Genetics 167 : 1791-1799, 2004.

21. Khatri P, Draghici S, Ostermeier GC and Krawetz SA: Profiling gene expression using onto-express. Genomics 79: 266-270, 2002.

22. Ginos MA, Page GP, Michalowicz BS, et al: Identification of a gene expression signature associated with recurrent disease in squamous cell carcinoma of the head and neck. Cancer Res 64: 55-63, 2004.

23. Draghici S, Khatri P, Bhavsar P, Shah A, Krawetz SA and Tainsky MA: Onto-Tools, the toolkit of the modern biologist: Onto-Express, Onto-Compare, Onto-Design and Onto-Translate. Nucleic Acids Res 31: 3775-3781, 2003.

24. Romer LH, Birukov KG and Garcia JG: Focal adhesions: paradigm for a signaling nexus. Circ Res 98: 606-616, 2006.

25. Ilic D, Furuta Y, Kanazawa S, et al: Reduced cell motility and enhanced focal adhesion contact formation in cells from FAKdeficient mice. Nature 377: 539-544, 1995.

26. Lee JW and Juliano R: Mitogenic signal transduction by integrinand growth factor receptor-mediated pathways. Mol Cells 17: 188-202, 2004.

27. Petit V and Thiery JP: Focal adhesions: structure and dynamics. Biol Cell 92: 477-494, 2000.

28. Lee H, Park DS, Wang XB, Scherer PE, Schwartz PE and Lisanti MP: Src-induced phosphorylation of caveolin-2 on tyrosine 19. Phospho-caveolin-2 $(\operatorname{Tyr}(\mathrm{P}) 19)$ is localized near focal adhesions, remains associated with lipid rafts/caveolae, but no longer forms a high molecular mass hetero-oligomer with caveolin-1. J Biol Chem 277: 34556-34567, 2002.

29. Kaech SM, Hemby S, Kersh E and Ahmed R: Molecular and functional profiling of memory CD8 T cell differentiation. Cell 111: 837-851, 2002 . 
30. Mao M, Biery MC, Kobayashi SV, et al: T lymphocyte activation gene identification by coregulated expression on DNA microarrays. Genomics 83: 989-999, 2004.

31. Adarichev VA, Vermes C, Hanyecz A, Mikecz K, Bremer EG and Glant TT: Gene expression profiling in murine autoimmune arthritis during the initiation and progression of joint inflammation. Arthritis Res Ther 7: R196-R207, 2005.

32. Liu K, Li Y, Prabhu V, Young L, Becker KG, Munson PJ and Weng N: Augmentation in expression of activation-induced genes differentiates memory from naive CD4+ T cells and is a molecular mechanism for enhanced cellular response of memory CD4+ T cells. J Immunol 166: 7335-7344, 2001.
33. Teague TK, Hildeman D, Kedl RM, et al: Activation changes the spectrum but not the diversity of genes expressed by T cells. Proc Natl Acad Sci USA 96: 12691-12696, 1999.

34. Yusuf I and Fruman DA: Regulation of quiescence in lymphocytes. Trends Immunol 24: 380-386, 2003.

35. Pages F, Berger A, Camus M, et al: Effector memory T cells, early metastasis, and survival in colorectal cancer. N Engl J Med 353: 2654-2666, 2005.

36. Wang E, Miller LD, Ohnmacht GA, et al: Prospective molecular profiling of melanoma metastases suggests classifiers of immune responsiveness. Cancer Res 62: 3581-3586, 2002. 